\title{
Revista

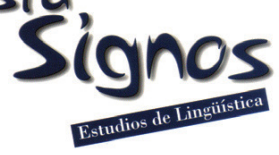

\section{E-lexicografía pedagógica especializada: Necesidades y usos en el campo del inglés científico-técnico}

\author{
Specialised pedagogical e-lexicography: Needs and usage in the \\ field of scientific-technical English
}

\author{
Nuria Edo Marzá \\ UNIVERSITAT JAUME I \\ ESPAÑA \\ nedo@ang.uji.es
}

Recibido: 29/IV/2014 / Aceptado: 02/XII/2015

\section{Resumen}

El objetivo principal de este artículo es determinar el uso dado por los estudiantes así como la percepción que éstos tienen de una herramienta a menudo desaprovechada, mal empleada e incluso infravalorada como es el diccionario. Según se desprende de este estudio, rara vez los estudiantes se detienen a reflexionar sobre qué informaciones necesitan en un diccionario, del mismo modo que rara vez una sola obra lexicográfica especializada contiene toda la información necesaria para solventar la totalidad de dudas de corte terminológico, conceptual o de uso que pueden plantearse. Es por ello que analizamos cómo perciben los estudiantes de inglés para ingeniería sus propios usos, necesidades y expectativas lexicográficas al ser preguntados explícitamente por ello mediante un sondeo basado en dos encuestas: una de análisis crítico de obras ya existentes y otra de usos y necesidades lexicográficas. Los resultados obtenidos muestran que ninguna obra conjuga todas las características de calidad, cantidad, claridad y accesibilidad de la información esperables en un e-diccionario científicotécnico, por lo que se apuntan mejoras concretas para optimizar estos aspectos atendiendo a los principios de la lexicografía pedagógica especializada (Fuertes-Olivera \& Arribas-Baño, 2008; Fuertes-Olivera, 2009) -que tanto puede enriquecer el proceso de enseñanza-aprendizaje del Inglés para Fines Específicos (IFE) - y al criterio de los propios usuarios potenciales: los alumnos. Este estudio pretende así promover un redescubrimiento del diccionario electrónico especializado como herramienta de aprendizaje y uso profesional con el fin de crear productos e-lexicográficos que fomenten el uso activo y eficiente del diccionario.

Palabras Clave: Lexicografía pedagógica especializada, e-lexicografía, diccionario especializado, Inglés para Fines Específicos (IFE), Inglés Científico-técnico. 


\begin{abstract}
The main objective of this paper is to determine the kind of usage made by students as well as their perception- of an often misused and even undervalued tool: the dictionary. This study shows that learners seldom reflect upon the kind of information they need in a dictionary, in the same way that a single specialised lexicographical work rarely contains all the information needed to solve all the terminological/conceptual/usage-related doubts that may arise. This is the reason why we have analysed how learners of English for Engineering perceive their own lexicographical usage, needs and expectations when explicitly asked about these aspects by means of two questionnaires: one of them dealing with the critical analysis of already-existing works and the other about lexicographical usage and needs. The results obtained show that no single text has all the quality, quantity, clarity and userfriendliness features to be expected in a scientific-technical e-dictionary. This is the reason why specific improvements have been signalled to optimise these aspects according to the principles of specialised pedagogical lexicography (Fuertes-Olivera \& Arribas-Baño, 2008; Fuertes-Olivera, 2009) -so enriching in the teaching-learning process of English for Specific Purposes (ESP) - and to the criteria of prospective users: the students. Hence, this study aims at promoting learners're-discovery of the electronic specialised dictionary as a useful learning and professional tool with the final objective of creating e lexicographical products that enhance the active and efficient use of dictionaries.
\end{abstract}

Key Words: Specialised pedagogical lexicography, e-lexicography, specialised dictionary, English for Specific Purposes and scientific-technical English.

\title{
INTRODUCCIÓN
}

Este artículo pretende promover el conocimiento y análisis de la manera en que los estudiantes emplean y perciben una herramienta de estudio y trabajo como el diccionario partiendo de la hipótesis de que se trata de una obra de consulta, aprendizaje y uso profesional a menudo desaprovechada, mal empleada e incluso infravalorada por parte del alumnado. La experiencia diaria en el aula de Inglés para Fines Específicos (IFE) nos muestra que pocas veces el aprendiz reflexiona en profundidad sobre qué informaciones necesita y pueden resultarle interesantes/útiles en un diccionario o sobre sus preferencias en los modos de presentación de la información. En este sentido, creemos además que rara vez se encuentra en una sola obra lexicográfica especializada -online o impresa- toda la información necesaria para solventar la totalidad de dudas lingüísticas, conceptuales o de uso de un estudiante. Partiendo de estas premisas iniciales, nuestro interés se ha centrado en conocer y analizar las opiniones al respecto del alumnado de una asignatura de IFE como es el Inglés Científico-Técnico (a la que nos referiremos de aquí en adelante también por su código dentro del plan de estudios en que se imparte: EX/AG 1005) con el fin de poder validar o refutar la hipótesis de partida. Nuestro estudio se basa además en los diccionarios a priori más utilizados por los estudiantes: los diccionarios especializados (en este caso científico-técnicos) online. En base a todo ello, el estudio tiene como objetivo principal conocer y mostrar cómo perciben los estudiantes las obras 
lexicográficas online a su disposición así como sus propios usos, necesidades y expectativas lexicográficas al ser preguntados explícitamente por ello de manera pautada mediante un sondeo basado en dos encuestas, una de análisis crítico de obras ya existentes, y otra de usos y necesidades lexicográficas. Del análisis cuantitativo, cualitativo y comparativo de los datos obtenidos en las encuestas se obtienen los resultados y conclusiones presentados en este estudio.

Pretendemos además, como proyección futura y objetivo final de la investigación en la que se origina y enmarca este estudio, que los resultados obtenidos constituyan la piedra angular de un proyecto que, en estadios posteriores, plantee y desarrolle un diccionario científico-técnico online, bilingüe, bidireccional y centrado en las distintas ingenierías en las que se imparte la asignatura EX/AG 1005. Se pretende promover así un redescubrimiento por parte de los aprendices del diccionario especializado que contribuya a la futura elaboración de productos e-lexicográficos mejor adaptados a las necesidades y demandas de los estudiantes-usuarios y que, además, fomenten su autonomía.

El estudio que aquí se presenta tiene por tanto vinculaciones a vertientes investigadoras, docentes y pedagógicas y, si bien por motivos de espacio no se abordarán todas en profundidad, se sustenta en los principios teóricos de la lexicografía pedagógica especializada (Fuertes-Olivera \& Arribas-Baño, 2008; FuertesOlivera, 2009) -concretamente en la e-lexicografía (Fuertes-Olivera \& Bergenholtz, 2011) pedagógica especializada- nutriéndose directamente de otros estudios y de otras áreas afines como la lingüística de corpus.

\section{Marco teórico}

\subsection{Estado de la cuestión: De los primeros estudios afines hasta el que nos ocupa}

Como ya se ha apuntado, al igual que ocurre en ámbitos lexicográficos más generales, también las obras de lexicografía pedagógica especializada (Fuertes-Olivera \& Arribas-Baño, 2008; Fuertes-Olivera, 2009) deben idealmente estar sustentadas en estudios empíricos del lenguaje de especialidad al que pretenden caracterizar, esto es, en muestras de lengua reales, representativas y fiables que procedan de y reflejen el aspecto de la realidad que tratan de describir, haciendo posible la validación o refutación de hipótesis atendiendo a elementos de referencia real y verdadera (Edo Marzá, 2009). La clave para ello puede ser el uso de corpus textuales que permitan el estudio de las unidades terminológicas in vivo. En este sentido, Hernández (2008) afirma que si los diccionarios didácticos dispusieran de corpus propios elaborados en base a sus objetivos, las obras gozarían de mayor rigor científico y utilidad

De igual modo, tal y como apunta Cabré (1993), los trabajos lexicográficos especializados no se pueden realizar en abstracto sino que deben estar siempre 
motivados por una necesidad profesional o de aprendizaje. Deben, además, regirse por los principios de calidad (o fiabilidad de los datos) y de adecuación, cubriendo tanto las necesidades profesionales como las funciones para las que se utilizarán y respetando por tanto el nivel de especialización requerido y esperado. De este modo, resultarán adecuados y coherentes siempre respecto a una situación comunicativa, esto es, a una actividad profesional, un ámbito temático, un contexto sociolingüístico, una función lingüística y unos usuarios prototípicos, siendo todo ello clave en el campo concreto de la lexicografía pedagógica especializada. Es por eso que Cabré (2009) considera que a la noción de 'buenas prácticas' (contar siempre con una entidad promotora, un objeto, un tema, unos destinatarios y un objetivo) debería asociársele la noción de 'adecuación' con el fin de producir no únicamente un trabajo de calidad en cuanto al proceso seguido y a la representación formal de los datos, sino también en cuanto a la utilidad del recurso para una situación sociolingüística dada.

Por otro lado, existen varios estudios sobre aspectos concretos analizados en el trabajo que aquí presentamos y que han contribuido, por tanto, a establecer y sustentar el diseño y la fundamentación teórica de este. Entre ellos, cabría mencionar el trabajo de De la Rosa (2003) acerca del uso que hacen los estudiantes de traducción de los diccionarios, en el cual se concluye que los diccionarios bilingües como herramienta para la búsqueda de equivalentes y la contextualización del término son los preferidos por los estudiantes, quienes a su vez desconocen cómo sacar el máximo partido de los diccionarios. Destacamos también los estudios de Baxter (1980) -que perfila las necesidades lingüísticas y hábitos de uso de los diccionarios en estudiantes universitarios japoneses de lengua inglesa-, o Snell-Hornby (1987), según el cual los diccionarios de lengua inglesa como lengua extranjera se utilizan, básicamente, para consultar usos, equivalencias, información gramatical y de pronunciación, y concluye que los estudiantes (universitarios suizos) requieren que aparezca más información del tipo sinónimos, variante geográfica o información enciclopédica en los diccionarios. Herbst y Stein (1987) también mostraron su interés por determinar la competencia en el uso del diccionario de los estudiantes universitarios de lengua inglesa como lengua extranjera en Alemania; el mal uso detectado radica, en su opinión, en una falta de motivación por parte del estudiantado más que en las propias deficiencias de las obras.

De manera más reciente, Martínez (2004) analiza cinco diccionarios de aprendizaje utilizados en la enseñanza de español como lengua extranjera (ELE), en los que detecta la carencia de información sintáctica y pragmática completa. También en el ámbito del ELE Alvar (2009) señala que no existe un diccionario válido que cubra todas las necesidades, sino que hay diferentes obras según la necesidad.

En cuanto a los estudios realizados sobre diccionarios online, Hernández (2008) presenta una reflexión acerca del uso de estos diccionarios en el aula de ELE, mientras que Águila (2009) aporta un análisis detallado de estos diccionarios en el que desgrana los retos actuales a los que la lexicografía debe hacer frente en este ámbito, como son, 
coincidiendo con el fin principal de nuestro estudio, la aplicación de lo que el denomina lexicografía escolar a los diccionarios electrónicos.

Nuestra investigación entronca con los estudios previos recién mencionados con el fin de, en el ámbito que nos ocupa -los diccionarios electrónicos de especialidad científico-técnica-, confirmar o refutar la hipótesis de partida planteada mediante un doble análisis complementario, más exhaustivo y ambicioso que los anteriormente mencionados y que puede resultar muy provechoso para la e-lexicografía pedagógica especializada: el de la perspectiva y expectativas de los aprendientes y el del análisis de obras reales para mejorarlas y/o crear otras nuevas que se adapten mejor a lo demandado por el usuario y sus necesidades.

\subsection{E-Lexicografia pedagógica especializada: Aspectos principales}

Como ya se ha descrito, la esencia de la lexicografía es su capacidad de concebir y producir herramientas de utilidad lingüística y comunicativa que puedan ser consultadas por usuarios concretos con el fin de adquirir la clase de información necesaria en diversas situaciones específicas (Tarp, 2013). Así, en concordancia con lo planteado en la sección anterior, autores como Bergenholtz y Tarp (2003, 2004) defienden que la lexicografía debe ser entendida como un área de práctica social relacionada con el análisis y elaboración de diccionarios que puedan satisfacer las necesidades comunicativas de un tipo de usuario concreto al que se le plantean problemas específicos relacionados con un tipo de situación de usuario concreta (Tarp, 2008). Este enfoque funcional de la lexicografía (llamada function theory of lexicography o theory of lexicographical functions) "shifts the focus from actual dictionary users and dictionary usage to potential users and the social situation in which they participate" (Tarp, 2008: 40). En consecuencia, y como apunta Fuertes-Olivera (2009), entender las implicaciones lexicográficas de diferentes situaciones sociales extralexicográficas es un ejercicio metalexicográfico necesario que puede arrojar algo de luz sobre las necesidades cambiantes de los usuarios potenciales. Por analogía, la esencia de la lexicografía para aprendices o lexicografía pedagógica (Binon \& Verlinde, 1999; Selva, Verlinde \& Binon, 2003) es su capacidad de concebir y producir herramientas útiles que puedan ser consultadas por tipos específicos de aprendices para satisfacer sus necesidades puntuales de información relacionadas con un proceso de aprendizaje global y en curso.

Si perfilamos un poco más todo lo apuntado, podemos decir que, según la lexicografía pedagógica especializada, en la elaboración de sus obras resulta fundamental partir de las cuatro categorías que son centrales a cualquier teoría lexicográfica orientada a aprendices: los usuarios, la situación de los usuarios, las necesidades de los usuarios y la asistencia o ayuda de los diccionarios (Tarp, 2008). Cualquier obra de lexicografía pedagógica especializada de calidad debe combinar 
eficientemente estos aspectos, siendo el análisis de su percepción por parte de los usuarios una de las claves del presente estudio. Es importante, además, tener en cuenta el concepto de 'accesibilidad' (rápida y fácil a los datos), clave en cualquier obra lexicográfica orientada al usuario y para la cual el entorno virtual ha contribuido sobremanera.

En esta misma línea, y tal y como señalan Bogaards (1994), Binon y Verlinde (1999) y Tarp (2005), la construcción de diccionarios pedagógicos especializados debe estar destinada a ayudar a los estudiantes de lenguajes para fines específicos a aprender unidades léxicas nuevas; relaciones entre unidades léxicas en términos de forma, pero sobre todo en términos de significado con el fin de aprender a discriminar unidades léxicas con aproximadamente el mismo significado, y a estructurar campos léxicos entre otros. Estos aspectos han sido precisamente los contemplados principalmente a la hora de diseñar los cuestionarios que fundamentan este estudio. Además, el dominio o campo, los contenidos, así como el metalenguaje empleado en el diccionario deben reflejar el nivel de conocimiento, comunicación y nivel educativo del usuario potencial de la obra.

Si atendemos a otros estudios sobre el tema, el llevado a cabo por Fathi (2014) referido también ámbito científico-técnico muestra una necesidad de revisión y mejora general de los actuales diccionarios especializados así como el hecho de que el rápido desarrollo del citado ámbito hace aún más acuciante la necesidad de actualizar regularmente dichos diccionarios que, de otro modo, perderían -como ya sucede- su validez y fiabilidad en poco tiempo.

Por todo ello, creemos que los e-diccionarios deben estar basados en la accesibilidad, actualidad, usabilidad y aprovechamiento máximo del medio digital, sin descuidar la cantidad ni calidad de las informaciones y sin perder nunca de vista las necesidades del usuario.

\section{Marco metodológico}

Partiendo de la fundamentación teórica expuesta en las secciones anteriores, la metodología empleada en este estudio para la recogida posterior análisis de datos se basó en el sondeo mediante encuesta anónima a los estudiantes de la EX/AG 1005. Dicho sondeo fue llevado a cabo en dos fases, esto es, durante dos medias sesiones de clase de una hora cada una que tuvieron lugar durante la misma semana lectiva en un aula con ordenadores. Los cuestionarios, diseñados por la autora/profesora, se presentaron a los alumnos de primer curso de IFE matriculados en la EX/AG 1005 del Grado de Ingeniería Mecánica -en el que la autora imparte docencia- de la Universitat Jaume I (Castellón, España). Esto se hizo a través del aula virtual de la asignatura, debiendo ser respondidos en clase bajo supervisión de la profesora. 
En la primera sesión se intentó determinar la necesidad real del estudio basándonos en los materiales (e-diccionarios) que los estudiantes tienen a su alcance en la red, por lo que 50 alumnos de la asignatura Inglés Científico-Técnico, impartida en el grado en Ingeniería Mecánica, respondieron al cuestionario 1: "Análisis crítico" (de obras lexicográficas online ya existentes. Durante la segunda sesión se pidió a estos 50 estudiantes que reflexionaran de manera crítica acerca del uso que hacen de los diccionarios especializados y las necesidades lexicográficas que creen tener como aprendices respondiendo al cuestionario 2: "Usos y necesidades". La atención de la profesora fue constante en todo momento puesto que los cuestionarios, si bien se diseñaron considerando la formación lingüística básica de los encuestados, podían plantear dudas que desvirtuaran los resultados y fiabilidad obtenidos. Las secciones 3.1 y 3.2 muestran cómo se plantearon dichos cuestionarios para ambas sesiones.

\subsection{Necesidad de este estudio: Análisis crítico de obras lexicográficas especializadas online ya existentes (cuestionario 1)}

El cuestionario 1 pretendía recabar datos sobre la percepción que los estudiantes tienen de obras lexicográficas especializadas online ya existentes y su utilidad real para la asignatura EX/AG 1005 y por ende de cara a mejorar su competencia en inglés científico-técnico. Partiendo de la lista de diccionarios/glosarios de ingeniería online de acceso libre que se proporciona a los estudiantes en el aula virtual de la asignatura, se seleccionaron 7 de ellos para este estudio con el fin de que los alumnos analizaran de forma crítica -en base al cuestionario planteado- las carencias y deficiencias de estas obras $^{2}$, debiendo asignar una puntuación entre el 1 (totalmente en desacuerdo) y el 5 (totalmente de acuerdo) a los 12 ítemes del cuestionario (véase Tabla 1) para cada uno de los 7 diccionarios analizados. Para responder a los ítemes planteados, además del propio cuestionario electrónico, se proporcionó a los estudiantes (también a través del aula virtual de la asignatura) un listado con 7 enlaces correspondientes a los 7 diccionarios a analizar. Las referencias y enlaces de dichos diccionarios (con fecha última de consulta 13/12/2013) se muestran abajo:

1. Engineering Network Dictionary

[http://www.engnetglobal.com/tips/glossary.aspx]

2. Engineering Terms Glossary

[http://www.engineersedge.com/engineering/Engineering_Terms_Glossary/ ]

3. Engineeringdictionary.org. [http://www.engineering-dictionary.org/]

4. Glossary of Engineering Terms

[http://www.contractorsunlimited.co.uk/glossary.shtml]

5. Sapiensman Technical Spanish-English Vocabulary.

[http://www.sapiensman.com/ESDictionary/index.htm] 
6. Science and Technology Dictionary de Babylon

[http://dictionary.babylon.com/science/]

7. Electrical Engineering Dictionary

[http://www.istanbul.edu.tr/eng2/jfm/ozcep/jeofizik/sozluk/Electrical.pdf]

Los 50 estudiantes que tomaron parte en el estudio trabajaron individualmente con los enlaces de los diccionarios online propuestos y se les requirió, con el fin de trabajar con parámetros comparables, que en todos los casos buscaran el término anneal (o su término más próximo) y otro término de su elección. Con el fin de ilustrar mejor la valoración de los estudiantes y los resultados obtenidos (sección 3), las Figuras 1 a 7 presentan las capturas de pantalla de la entrada anneal o su término más próximo/afín según cada diccionario.

En el caso del Diccionario 1 (Figura 1), se trata de una obra monolingüe cuya entrada analizada únicamente incluye la definición del término a la vez que se hace referencia a una combinación léxica relacionada (fully annealed aluminium) integrada en la misma línea de la definición. No obstante, el número de entradas totales a disposición del usuario es amplio.

\section{Anneal}

To heat a metal to a temperature slightly below its melting point, then cool it gradually so as to soften it thoughly. Fully annealed aluminium is said to be in the "0" temper.

Figura 1. Diccionario 1: Engineering Network Dictionary. Entrada: anneal.

En la entrada analizada del Diccionario (glosario monolingüe) 2 (Figura 2) se incluyen secciones claramente diferenciadas: una categorización del término según su letra inicial, el término en sí, su descripción (definición) y la fecha de creación de la entrada. Resulta útil la inclusión de la fecha de incorporación de la entrada para ser conscientes de la actualidad y por tanto vigencia de la información en un área tan cambiante como la tecnológica. Cabe mencionar como dato desfavorable la presencia de un error ortográfico en el propio término consultado (anealing* en vez de annealing), resultando curioso, además la poca funcionalidad del modo de búsqueda, que no permite introducir directamente el término a consultar sino que hace necesario buscarlo entre el resto de palabras con la misma inicial.

\section{Category: $\underline{A}$}

Term: anealing

Description: heating a metal to, and holding at, a suitable temperature and cooling at a suitable rate so as to reduce hardness, improve machineability, ease cold working, etc.

Date: Sep 16, 2009

Figura 2. Diccionario 2: Engineering Terms Glossary. Entrada: an(n)ealing. 
El tercer diccionario estudiado (Figura 3) corresponde al Engineeringdictionary.org, un diccionario-glosario inclusivo de todas las ramas de ingeniería y monolingüe pero que incluye el software traductor de Babylon (a 75 idiomas). Se trata de un diccionario basado fundamentalmente en la definición (bastante extensa y detallada) del término. La entrada analizada incluye dos definiciones del término procedentes de fuentes distintas (con enlace a la fuente) y una serie de palabras relacionadas, si bien no se aprecia la relación que puede existir entre algunos de los términos sugeridos como query o e-mail.

\section{Definition Of:}

\section{ANNEAL}

\section{Dictionary of Automotive Terms}

To remove hardness from metal by heating, usually to a red color, then allowing it to cool slowly. Unlike steel, copper is annealed by heating, and then plunging it into cold water. It is the reverse of hardening.

No Dictionary Found

To soften by heating and allowing to cool slowly.

See also: DASHPOT, Query, E-mail, DAT, WATER HAMMER

Figura 3. Diccionario 3: Engineeringdictionary.org. Entrada: anneal.

En el Diccionario 4 (Figura 4), también monolingüe, la información incluida en la entrada analizada corresponde únicamente a la definición de los diferentes términos. En esta y en todas las entradas consultadas en este diccionario aparece la posibilidad de recibir más información a través de la opción further Reading que, sin embargo, no se encuentra operativa en ningún caso (se trata de un enlace inactivo sin información complementaria).

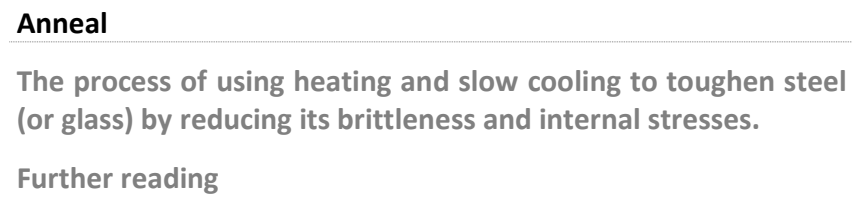

Figura 4. Diccionario 4: Glossary of Engineering Terms. Entrada: anneal.

El Diccionario 5 (Figura 5) es un diccionario especializado, actualizado semanalmente, que abarca todas las ramas de la ingeniería. Se trata probablemente el diccionario con mayor cantidad de términos e información útil para aprendices de cuantos estamos analizando, si bien su interfaz resulta poco accesible y 'amigable' (user-friendly), pudiendo aprovecharse mejor las múltiples posibilidades del medio virtual. Incluye en sus entradas (en muchos casos exclusivamente) el equivalente del término en español, además de -como en el caso de la entrada que aquí analizamos- 
extensas definiciones/descripciones, sinónimos o denominaciones alternativas, términos relacionados, combinaciones, acepciones y área temática, todo ello también en español. No obstante, el motor de búsqueda no permite buscar un término concreto sino que hay que navegar por todos los términos de una determinada letra hasta dar con el que se busca, lo cual supone una desventaja importante por el gran número de términos que incluye, que hace el proceso de búsqueda poco funcional y lento, desaprovechando gran parte de las posibilidades del medio digital.

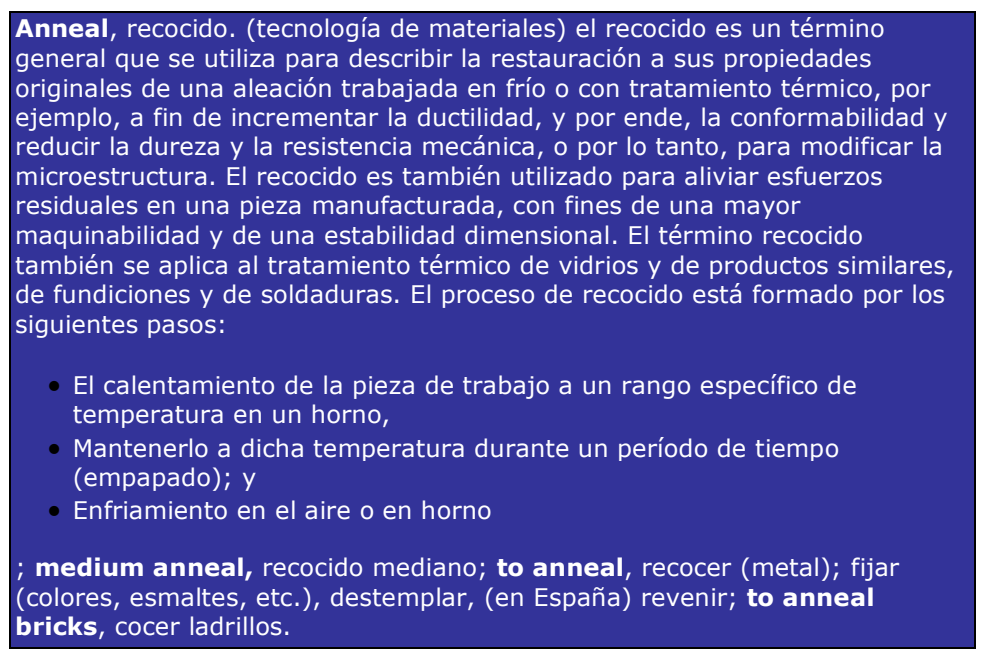

Figura 5. Diccionario 5: Sapiensman Technical Spanish-English Vocabulary. Entrada: anneal.

El Diccionario 6 (Figura 6) presenta la ventaja de incorporar entradas de diversos diccionarios/fuentes para el término consultado, pudiendo discutirse el carácter académico de algunas. Puede resultar confuso en los modos de presentación precisamente por nutrirse de varias fuentes y mostrarlas todas, lo que a su vez también sería ventajoso al proporcionar informaciones diversas en una sola búsqueda, incluyendo datos tanto de fuentes especializadas, generales y populares. Entre los datos incluidos en la(s) entrada(s) analizada(s) observamos principalmente definiciones (o descripciones), acepciones y sinónimos. 
( $v . t$. )

To subject to great heat, and then cool slowly, as glass, cast iron, steel, or other metal, for the purpose

of rendering it less brittle; to temper; to toughen.

(v. t.)

To heat, as glass, tiles, or earthenware, in order to fix the colors laid on them.

Webster's Revised Unabridged Dictionary (1913), edited by Noah Porter. About

hEnglish - advanced version

lanneal as. an\&? lan; an on + \&?;lan to burn; also oe anelen to enamel, prob. influenced by of. neeler, nieler, to put a black enamel on gold or silver, f. nieller, fr. II. nigellare to blacken, fr. I. nigellus blackish, dim. of niger black. cf. niello, negro.]

1. to subject to great heat, and then cool slowly, as glass, cast iron, steel, or other metal, for the

purpose of rendering it less brittle; to temper; to toughen

2. to heat, as glass, tiles, or earthenware, in order to fix the colors laid on them.

anneal

$\checkmark$ : anneal or toughen by a process of gradually heating and cooling; "temper glass" [syn: temper]

Dictionary of Automotive Terms

Engineering Dictionaries

To remove hardness from metal by heating, usually to a red color, then allowing it to cool slowly. Unlike

steel, copper is annealed by heating, and then plunging it into cold water. It is the reverse of hardening

Technical English by wpv

To soften by heating and allowing to cool slowly

Anneal Definition from Computer \& Internet Dictionaries \& Glossaries

Integrated Circuit Terminology

a heating and cooling process designed to reduce stress

Hardware Dictionaries

Copyright $\odot 2000$ - 2006 IC Knowledge LLC. All rights reserved.

Anneal Definition from Encyclopedia Dictionaries \& Glossaries

Anneal Definition from Encyclopedia Dictionaries \& Glossaries

Wikipedia English - The Free Encyclopedia

Annealing may refer to:

Annealing (metallurgy), a heat treatment that alters the microstructure of a material causing changes in properties such as strength and hardness and ductility

Annealing (glass), heating a piece of glass to remove stress

Nucleic acid thermodynamics, includes the annealing of DNA or RNA pairing by hydrogen bonds to a

complementary sequence, forming a double-stranded polynucleotide

Simulated annealing, a technique for searching for a solution in a space otherwise too large for ordinary search methods to yield results

Quantum annealing, a method for finding solutions to combinatorial optimisation problems and ground states of glassy systems using quantum fluctuations

See more at Wikipedia org

Figura 6. Diccionario 6: Science and Technology Dictionary. Entrada: anneal.

Finalmente, el diccionario 7 (Figura 7) es una obra monolingüe útil desde el punto de vista del número de entradas e informaciones contenidas pero que desaprovecha las posibilidades del medio digital, ofreciendo, sin embargo, la posibilidad de ser 
impreso de forma sencilla. Se trata de un diccionario en PDF colgado en la red, basado en la definición y en la información enciclopédica y que ofrece al usuario remisiones a términos relacionados.

annealing a process often used in semi-
conductor processing to cause a change in
materials or device properties to improve the
circuit performance and/or reliability. See
also simulated annealing.

Figura 7. Diccionario 7: Electrical Engineering Dictionary. Entrada annealing.

Una vez respondido el cuestionario 1 por parte de los estudiantes, los datos fueron procesados y los resultados obtenidos se analizan e interpretan en la sección 3.

\subsection{Usos y necesidades lexicográficas de los estudiantes (cuestionario 2)}

En un estudio como el planteado aquí, basado en los principios de la lexicografía pedagógica especializad a en un medio digital y ubicado dentro de un ámbito epistemológico muy específico -el científico-técnico-, resulta fundamental saber qué tipo de necesidades tienen los estudiantes y qué esperan de un diccionario en el proceso de enseñanza-aprendizaje del inglés de especialidad. Por ello, tras el análisis crítico de obras ya existentes (cuestionario 1), con el fin de conocer la percepción del estudiantado sobre sus propias necesidades lexicográficas se diseñó el cuestionario 2, que consta de 24 preguntas (Tabla 2, sección 3.2) y que indaga sobre el uso real que hacen los estudiantes de los diccionarios especializados y sobre qué tipo de información consideran relevante y porqué de acuerdo a sus necesidades, expectativas y percepción individual. Los cuestionarios 1 y 2 fueron diseñados en base a parámetros similares o comparables, considerados clave en la lexicografía especializada, por lo que los resultados obtenidos son representativos de una realidad concreta en base a la cual poder crear obras lexicográficas especializadas mejores para nuestros estudiantes.

\section{Resultados}

Es necesario apuntar que la ciencia y la tecnología son dos campos complementarios que engloban multitud de subáreas de especialidad, muchas de ellas de carácter sumamente complejo, intrincado y cambiante. Bien sea por su afán de extralimitarse o 'infralimitarse' en cuanto a temática y número de términos, por la poca versatilidad y funcionalidad en los modos de presentación, por la falta de información o por el tratamiento que se hace de ella, son muchos los diccionarios científicotécnicos que pueden encontrarse hoy en día en Internet pero son muy pocos los que, según se desprende de este estudio y de nuestra propia experiencia, cumplen satisfactoriamente con las necesidades y expectativas de los aprendices y con los 
principios de la e-lexicografía especializada. Pese a todo, sí creemos que puede y debe hacerse un esfuerzo por cubrir las necesidades terminológicas detectadas en los alumnos de IFE, pudiendo constituir los resultados obtenidos aquí un buen punto de partida, necesario además para dicho fin. Se presentan a continuación los resultados obtenidos en ambos cuestionarios (apartados 3.1 y 3.2) así como una breve valoración conjunta/comparativa de aquellos datos obtenidos que a priori resultan más llamativos o relevantes (apartado 3.3).

\subsection{Resultados del cuestionario 1: Percepciones sobre diccionarios ya existentes}

En cuanto a los resultados que se desprenden del cuestionario 1, los gráficos de la Tabla 1 muestran tendencias e ilustran los resultados obtenidos para cada diccionario en cada uno de los 12 ítemes del cuestionario, desgranándose a continuación los más significativos.

Según las respuestas de los estudiantes, los diccionarios 5 y 6 son aquellos que proporcionan una información más clara y útil de cara a entender plenamente el concepto al que se refiere el término (ítem 1), siendo los diccionarios 1 y 7 los que menos favorecen o ayudan a dicha comprensión y muestran claras carencias a la hora de mostrar el término en uso (ítem 2). Los resultados muestran también que ningún diccionario proporciona información relativa a la pronunciación del término (ítem 3) solo el diccionario 6 fue considerado de alguna utilidad a este respecto por el 8\% de los estudiantes. En cuanto a la inclusión de acepciones, derivados y compuestos (ítem 4), los estudiantes vuelven a considerar los diccionarios 5 y 6 como los más completos, mientras que solo el diccionario 5 proporciona equivalentes (ítem 5), tratándose en el resto de casos de obras monolingües. Ningún alumno encontró información acerca del área o subáreas temáticas (ítem 6) a las que pertenece el término a excepción de en los diccionarios 5 y 6 . En cuanto a la inclusión de referencias cruzadas para facilitar la relación del término con otros afines (ítem 7), los estudiantes consideraron los diccionarios 3, 6 y 7 como los más completos.

Ningún estudiante consideró tampoco que los diccionarios analizados le proporcionaran información sobre la categoría gramatical del término (ítem 8) a excepción del número 6. En cuanto a la posible utilidad de los distintos diccionarios en base al número de términos que incluyen (ítem 9), los estudiantes consideran los diccionarios 5 y 6 como los más útiles para la asignatura y, según el ítem 10, también para su futura vida profesional. Los diccionarios considerados como visualmente menos atractivos y claros en su manera de presentar la información (ítem 11) fueron los diccionarios 1 y 4 , y en cuanto a la facilidad de manejo, funcionalidad y adaptación al medio digital (ítem 12) todos los diccionarios obtienen puntuaciones similares, no destacando ninguno a excepción del 6. 
Tabla 1. Resultados del cuestionario 1 presentados gráficamente e ítemes valorados en el mismo.

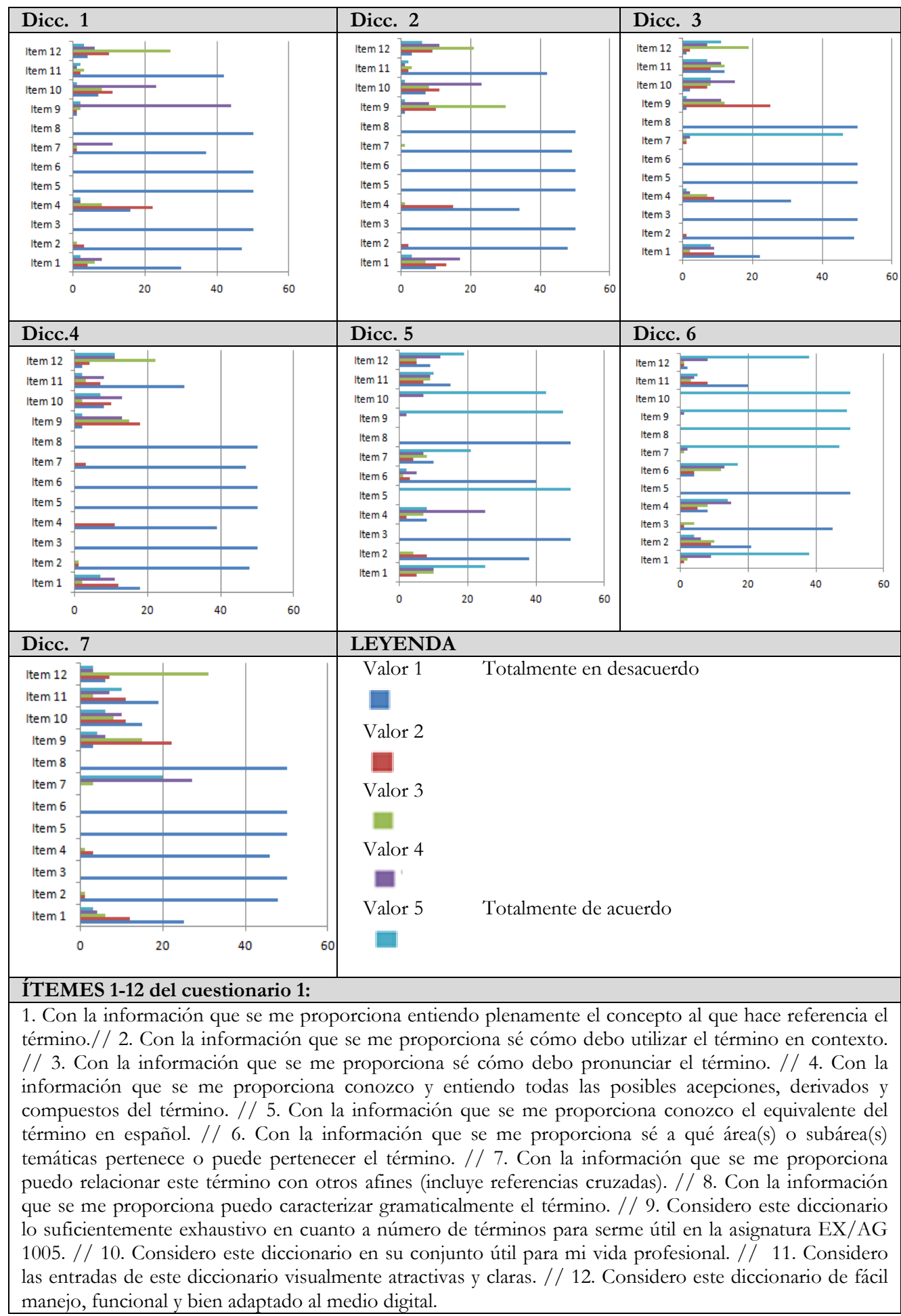


De acuerdo a los resultados obtenidos en este primer cuestionario podemos afirmar que, si bien en todos los casos se trata de diccionarios válidos y útiles en cierta medida, ninguno parece cumplir con todas las características esperadas y esperables en un e-diccionario para los aprendices de la EX/AG 1005, bien porque la información que presentan es muy escasa, porque no se corresponde con las necesidades que los estudiantes de IFE pueden tener (por ejemplo, no incluye equivalente en la lengua madre de los estudiantes), porque los motores de búsqueda habilitados son poco o nada funcionales o porque los datos se presentan de manera confusa, mezclada y poco visual, entre otros motivos. Así, ninguno de los diccionarios analizados, a excepción del 3 (que incluye el software traductor de Babylon a 75 idiomas) y el 5, ofrecen equivalentes en otras lenguas, siendo este un aspecto importante en cualquier diccionario para aprendices de una lengua extranjera, tal y como se desprende también de los resultados obtenidos en la pregunta 8 del cuestionario 2. En todos los casos se proporciona información de consulta útil pero más bien escasa y dirigida, según parece, a un perfil de usuario más bien profesional. Se trata además de una información basada fundamentalmente en la descripción y la definición en la que no se proporciona ningún tipo de información lingüística complementaria (tipo categoría gramatical o de naturaleza colocacional de los términos (a excepción del 6)) ni tampoco información sobre el uso real de los términos en contexto. En ninguno de los diccionarios analizados apreciamos la inclusión de ejemplos de uso ni de imágenes ilustrativas del término, algo que, dado el medio digital en el que se encuentran los diccionarios, podría haber sido explotado y que consideramos especialmente importante para el usuario-aprendiz. Son además muy pocos (únicamente el 5 y el 8) los diccionarios que incluyen el área temática, importante para la correcta comprensión y ordenación del conocimiento por parte del estudiante. Por su parte sólo los diccionarios 3 y 7 incluyen referencias cruzadas y remisiones que puedan ayudar al estudiante a relacionar el término dentro de su campo y ninguno hace referencia a la pronunciación del mismo. Además, como ya hemos dicho, en casos como el 5 la funcionalidad en el modo de búsqueda es prácticamente nula, lo cual contraviene cualquier posible orientación pedagógica así como el concepto clave de 'accesibilidad'. Algo similar ocurre con el diccionario 7, en formato PDF, que podría explotar mucho más las posibilidades del medio digital en cuanto a la recuperación y enlace de informaciones.

De las respuestas de los estudiantes se desprende que no hay ningún diccionario online actualmente en la $W e b$ (al menos de entre los analizados) que cubra o satisfaga plenamente las necesidades de los estudiantes de la EX/AG 1005, a lo que se suma, tal y como ya hemos anticipado y como veremos a continuación, el poco y mal uso dado a los diccionarios por parte de los alumnos y su desconocimiento de los mismos como herramienta de aprendizaje. 


\subsection{Resultados del cuestionario 2: Percepciones de usos y necesidades lexicográficas}

Los resultados (y las propias cuestiones) del cuestionario 2 se presentan de manera numérica y gráfica, según se ha considerado más ilustrativo, en la Tabla 2, detallándose y comentándose a continuación los resultados más significativos.

Tabla 2. Resultados (y cuestiones) del cuestionario 2.

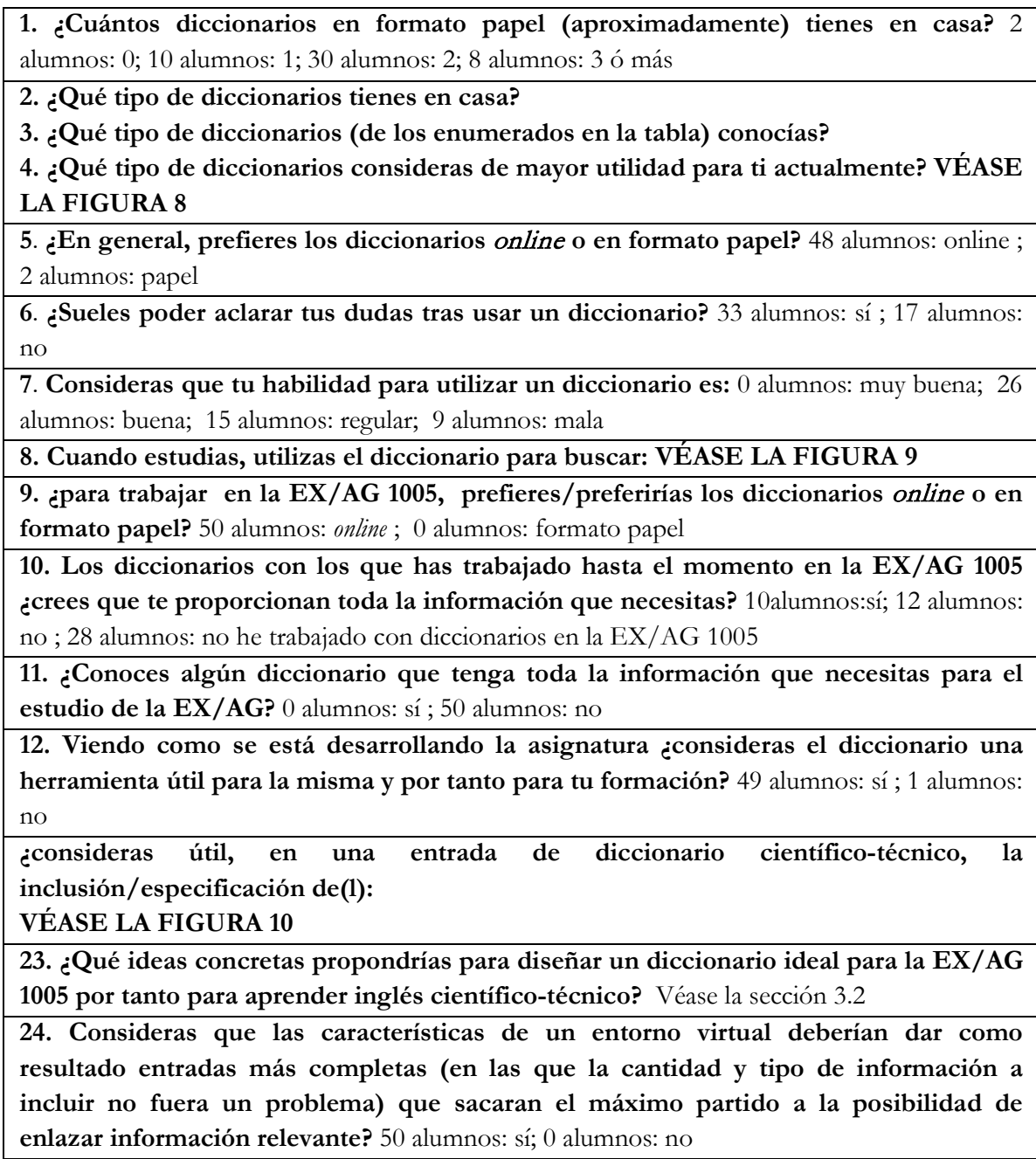

Según la pregunta número 1 el 4\% de los alumnos encuestados afirma no poseer ningún diccionario en formato papel, mientras que el 20\% tiene 1 diccionario, el 60\% tiene 2 diccionarios, y el 16\% dice tener 3 o más. En cuanto a los tipos de diccionarios (ítem 2) que los alumnos tienen-, el $86 \%$ de los alumnos que respondieron a esta cuestión afirmaron tener un diccionario de la lengua, el 96\% afirmó tener un diccionario de idiomas, un 4\% dijo tener un diccionario de sinónimos y antónimos 
mientras y un 14\% manifestó poseer un diccionario especializado. Únicamente un estudiante dijo tener un tesauro. En relación a los tipos de diccionarios conocidos por los estudiantes (pregunta 3), los de lengua, los de idiomas y los especializados son los más conocidos. Según la pregunta 4 (véase el Gráfico 1), el especializado y de idiomas y el de lengua fueron señalados por la gran mayoría de los alumnos como los diccionarios de mayor utilidad dadas las necesidades de los estudiantes.

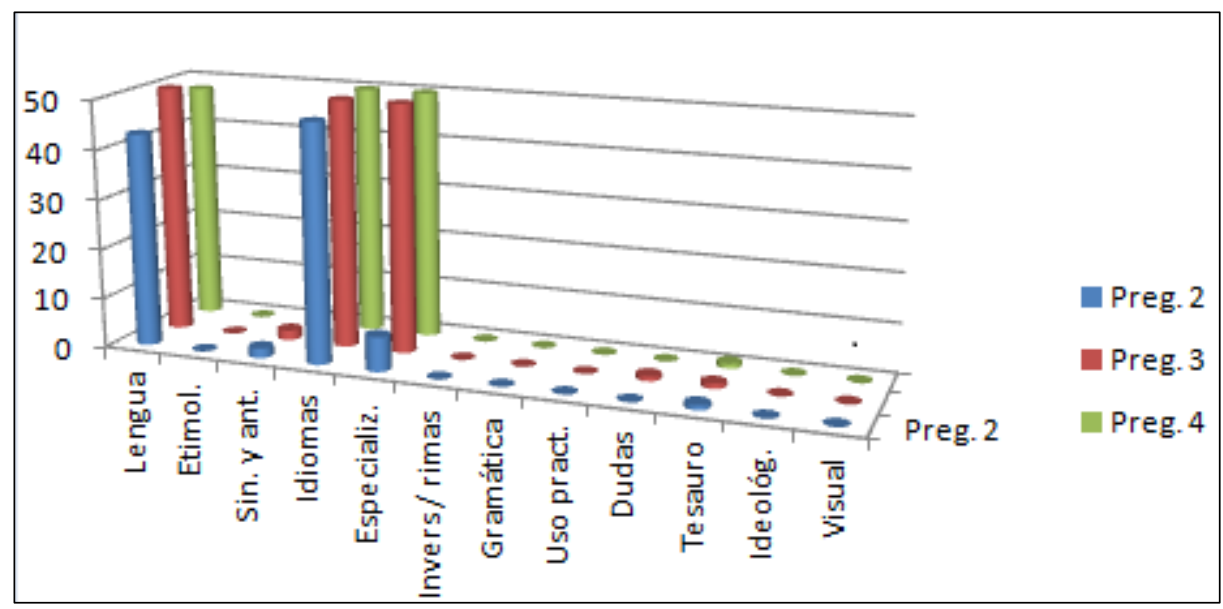

Gráfico 1. Diccionarios que los estudiantes poseen, conocen y consideran de mayor utilidad (preguntas 2 a 4).

La pregunta 5 dio como resultado que un $96 \%$ de los estudiantes indicara su clara preferencia por los diccionarios online a la hora de hacer consultas en general, aduciendo la rapidez de la consulta, su carácter gratuito y las ventajas de poder enlazar información e incluir mayor cantidad de la misma. Así pues, de las respuestas obtenidas en las preguntas 1 a 5 parece desprenderse un conocimiento bastante limitado de la variada tipología de diccionarios al servicio del aprendiz y del usuario en general así como una clara -y nada sorpresiva- preferencia por formatos y entornos virtuales.

Por otro lado, más de la mitad $(66 \%)$ de los alumnos afirmó que sí suele poder aclarar sus dudas tras usar un diccionario (pregunta 6). Entre los motivos aducidos por quienes respondieron negativamente $(34 \%)$ cabe destacar nuevamente la difícil interpretación de las informaciones contenidas así como la falta de ejemplos de uso ilustrativos. Además, se apuntó la dificultad, en muchos casos, de elegir la acepción correcta del término, mencionándose también aspectos relacionados con la microestructura de la entrada, que hacen que, con frecuencia, las informaciones resulten densas, poco claras y confusas. En esta misma línea, se apuntó el hecho de que 'uno nunca encuentra exactamente lo que busca', ‘todo aparece mezclado' y 'la forma de expresión es muy enrevesada'. Cabe destacar que ningún estudiante considera su habilidad en el manejo de diccionarios (ítem 7) muy buena, si bien un 
$52 \%$ la considera buena, un 30\% regular y un 18\% mala. Entre los estudiantes que calificaron su habilidad como regular o mala cabe destacar que, nuevamente, aludieron a su incapacidad de interpretar o entender algunas o muchas de las informaciones del diccionario y apuntaron también a la falta de costumbre como un posible motivo, si bien el más esgrimido fue que nunca han sido instruidos para aprovechar todo el potencial de un diccionario, 'descifrar' su información y sacarle por tanto el máximo provecho. Más bien siempre se ha dado por hecho en su contexto educativo que un diccionario se aprendía a usar de forma autodidacta y no requería, por tanto, de mayores indicaciones. Así, por lo que se desprende de estos resultados, parece necesario, tal y como apunta Ciro (2007), enseñar al estudiante que lo importante al acercarse a un diccionario no es únicamente conocer el significado de una palabra, sino aprender a usarla, para lo cual es fundamental enseñarle a utilizar de manera efectiva el diccionario. Para fomentar ese buen uso y conocimiento del diccionario, Martín (2001) apunta a la necesidad de conocer los diversos tipos de diccionarios; conocer la estructura del diccionario (ordenación, estructura de una entrada, informaciones contenidas, ejemplos, etc.); saber interpretar la información semántica y gramatical que proporcionan las entradas de los diccionarios; comprender las definiciones y los ejemplos, y desarrollar actitudes activas respecto a la búsqueda de información y al interés por la precisión. Precisamente con la adquisición del conocimiento necesario, el diccionario dejará de ser un escollo más para la comprensión convirtiéndose en su gran aliado. En cuanto a los resultados obtenidos en la pregunta 8 (véase el Gráfico 2), estos muestran que sólo los equivalentes y las definiciones son consultados de manera más o menos frecuente por los estudiantes.

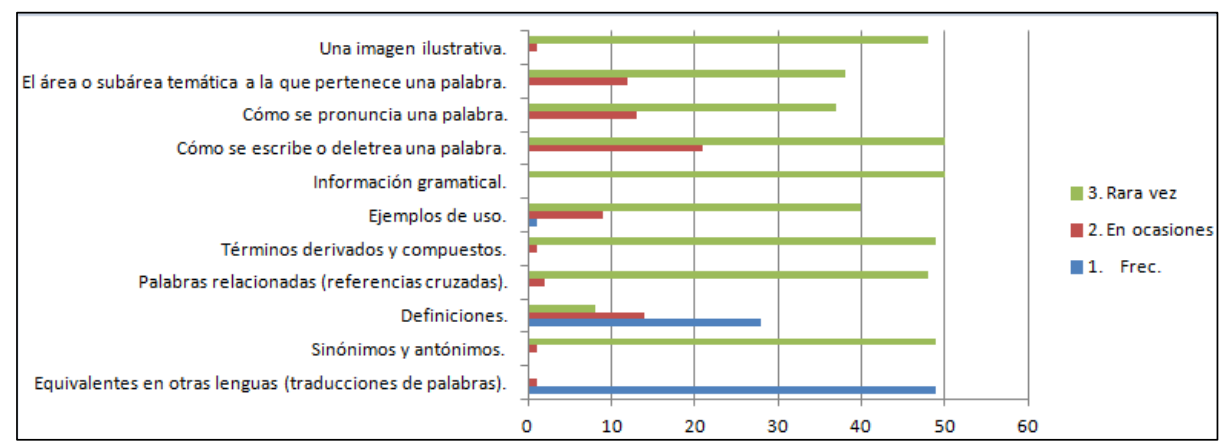

Gráfico 2. Frecuencia de consulta de informaciones en los diccionarios por parte de los estudiantes (pregunta 8).

Por otro lado, al ser preguntados por sus preferencias respecto a los diccionarios online o en formato papel (pregunta 9) a la hora de trabajar en la asignatura EX/AG 1005, el 100\% de los alumnos encuestados afirma preferir los diccionarios online por ser mucho más funcionales y rápidos. Les gusta además el hecho de que algunos de los que conocen incluyan grabaciones de audio con la pronunciación del término en cuestión y también la posibilidad de consultar varios diccionarios a la vez de manera 
rápida y sencilla. El coste nulo de la gran mayoría de ellos es también un argumento importante. De igual modo, el hecho de que las entradas puedan incluir enlaces a informaciones relacionadas es también un aspecto positivamente valorado, así como la posibilidad, clave en el área científico-técnica, de actualizarlos y ampliarlos de manera sencilla e inmediata. Parece evidente que el uso del diccionario online es el presente de las prácticas pedagógicas lexicográficas - lo cual no resulta sorpresivo si consideramos que se trata de usuarios que, por edad, son ya nativos tecnológicos- y su relevancia debe necesariamente considerarse a la hora de instruir en el uso del diccionario.

El 56\% de los alumnos afirmó no haber trabajado nunca con diccionarios en la EX/AG1005 (ítem 10). Del 44\% restante, el 45,5\% dijo que los diccionarios utilizados sí le proporcionaron la información necesaria en ese momento mientras que el 54,5\% contestó negativamente, esgrimiendo principalmente la falta de ejemplos de uso, la poca claridad de las definiciones y la dificultad de interpretar informaciones 'menos comunes'. A su vez, ningún estudiante manifestó conocer ningún diccionario con toda la información necesaria para el estudio del inglés científico-técnico (ítem 11). Respecto a la pregunta 12 , pese al poco uso reflejado en la pregunta 10 , el $98 \%$ de los estudiantes considera el diccionario (en general) una herramienta útil para la EX/AG 1005 dado el modo en que se desarrolla la asignatura, principalmente porque les permite conocer el equivalente en su lengua madre de muchos términos así como clarificar conceptos. El 2\% restante considera que el diccionario no les resulta de utilidad puesto que no saben utilizarlo bien y nunca encuentran exactamente aquello que buscan. Por todo ello y de acuerdo a lo referido hasta el momento, parece necesario hacer un replanteamiento de tres aspectos básicos: qué necesitan los estudiantes de un diccionario, cómo debemos atender dichas necesidades en cuanto a la forma de darles respuesta en un diccionario y cómo enseñar al estudiante a optimizar la información que le proporcionan los diccionarios.

En lo concerniente a las informaciones que un diccionario de especialidad para aprendices debería contener (preguntas 13 a 22, véase el Gráfico 3), el 100\% de los alumnos considera útil la inclusión de equivalentes en otras lenguas (pregunta 13) siempre y cuando éstas incluyan su lengua madre- porque frecuentemente la 'traducción' del término es la única información que se les requiere o que dicen necesitar para comprender un concepto. Abundando un poco más en los estudios anteriores realizados al respecto (Corpas, Leiva \& Valera, 2001; Azorín \& Climent, 2003) cabe indicar que estos muestran la primacía del diccionario bilingüe sobre los monolingües de aprendizaje en el uso real que se hace del diccionario en el aula. De hecho, según Santamaría (2004), el rol fundamental desempeñado por los diccionarios bilingües parece obedecer a que los estudiantes se sienten más cómodos y seguros comparando las estructuras léxicas y sintácticas entre su lengua materna y la lengua que están aprendiendo. Respecto a la pregunta 14, el 100\% de los alumnos considera útil la inclusión de contextos ilustrativos/ejemplos reales de uso porque con 
frecuencia les resulta más clarificador que la propia definición y porque el correcto uso del término (y de la lengua) es a lo que aspira el estudiante y futuro profesional; es por ello que se necesitan muestras reales y bien construidas en las que basar su propia producción y/o comprensión del término. De hecho, según Alonso (2013), los ejemplos incluidos en un medio electrónico pueden y deben desempeñar un papel más importante puesto que los aprendices valoran los ejemplos más que cualquier otra cosa. En lo relativo a la pregunta 15 , el $76 \%$ de los alumnos no considera útil la inclusión de la transcripción fonética de un término porque afirma no tener los conocimientos necesarios para su correcta interpretación ni 'lectura'. El otro $24 \%$ reconoce la importancia de dicha información porque para el correcto y completo desarrollo de la competencia lingǘstica, aspectos de la oralidad como son la pronunciación y la inteligibilidad resultan clave. Sin embargo, el 100\% de los estudiantes está de acuerdo en que la inclusión de archivos de audio con la pronunciación del término es altamente recomendable y útil (pregunta 16). El 96\% de los alumnos considera útil la inclusión de las expresiones derivadas y compuestos de un término (pregunta 17) porque se trata de información relevante que puede serles de utilidad. En lo relativo a la pregunta 18, el 92\% considera útil la inclusión de términos afines o relacionados (referencias cruzadas) porque esto les permite establecer vínculos y entender mejor las relaciones entre conceptos. El 68\% de los estudiantes que participaron en el estudio afirmaron considerar útil la especificación del área temática en la entrada (pregunta 19) porque les ayudaba a entender y relacionar mejor el concepto y el $72 \%$ de los estudiantes afirmó considerar útil la inclusión de posibles sinónimos (pregunta 20) por serles especialmente práctica a la hora de escribir textos, mientras que el $28 \%$ restante afirmó no necesitar dicha información normalmente y por tanto no considerarla útil. En lo referente a la pregunta 21, el $98 \%$ de los estudiantes no considera útil la inclusión de información gramatical principalmente por desconocimiento de algunas de estas categorías y por no alcanzar a comprender la aplicabilidad de dicha información. Esta visión no coincide, sin embargo, con la de la mayoría de académicos. Según Santamaría (2004), en el proceso de aprendizaje de una lengua tanto los conocimientos tanto léxicos como gramaticales están unidos de forma indisoluble y debe quedar reflejada en los distintos materiales e instrumentos que utilizan los estudiantes durante su proceso de aprendizaje, entre los que destaca el diccionario. Pese a todo, todos los estudiantes manifestaron consultar ese tipo de información 'rara vez' (ítem 8-g, cuestionario 2). Finalmente, el 100\% de los alumnos consideraría útil la inclusión de dibujos/fotografías ilustrativos (pregunta 22) porque 'una imagen vale más que mil palabras' y 'muchos conceptos se entenderían mejor'. 


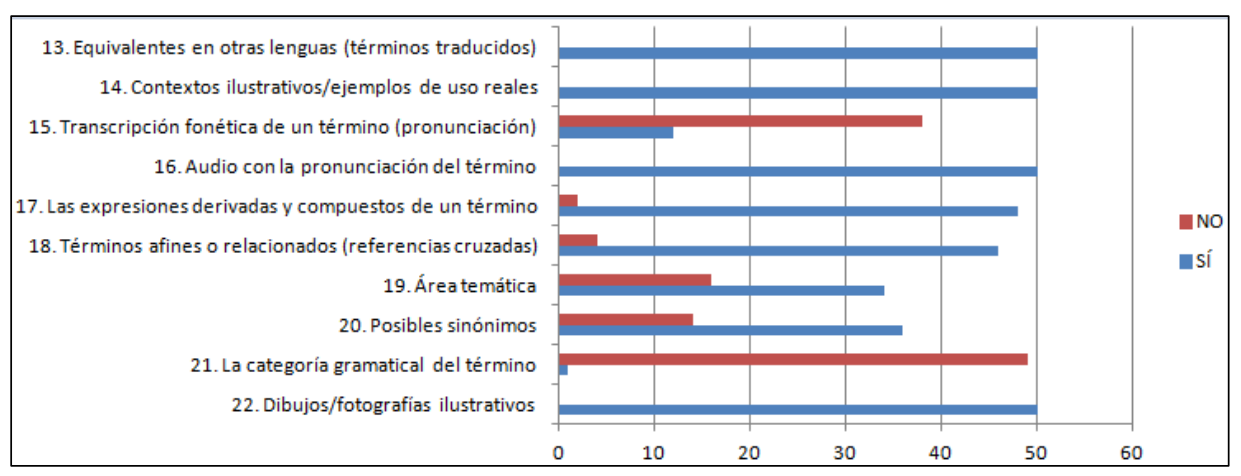

Gráfico 3. Informaciones que un diccionario de especialidad para aprendices debería contener según los propios estudiantes (preguntas 13 a 22).

Respecto a las ideas concretas propuestas por los estudiantes para diseñar un diccionario online idóneo para la EX/AG 1005 (ítem 23), la gran mayoría parece estar de acuerdo en la necesidad de simplificar o clarificar la microestructura de los diccionarios de modo que las distintas informaciones aparezcan de manera clara. Se apunta también la conveniencia de no incluir informaciones poco relevantes que sólo contribuyan a 'ensuciar' o 'liar' la entrada. Resultan especialmente interesantes las ideas concretas aportadas: se propone la inclusión de ejemplos de uso reales para todas las acepciones y la traducción de dichos ejemplos (algo que no suele realizarse en ninguna obra que conozcamos) y se resalta el hecho de que al tratarse de un diccionario online el espacio no supone, a priori, un problema, por lo que la inclusión de varios contextos o ejemplos de uso originales (y traducidos) sería un aspecto positivo a considerar. Los estudiantes proponen sacar el máximo partido a la posibilidad de enlazar información y sugieren incluso lo beneficioso que resultaría enlazar entradas entre varios diccionarios. Creen también que podría sacarse un mayor partido a la inclusión de audio (e incluso de vídeo) y consideran que las definiciones deberían ser más claras, menos enrevesadas en su redacción, y más acordes al público al que se dirigen. En lo relativo a la pregunta 24 (y en concordancia con los resultados de la pregunta 23), el $100 \%$ de los estudiantes considera que las características de un entorno virtual deberían resultar en entradas más exhaustivas y completas precisamente porque la cantidad de información no supone un problema, si bien esa información debería ordenarse de manera clara, sistemática y lógica, incluyendo solo información pertinente y 'entendible' en pos de la usabilidad y claridad del diccionario y evitando en la medida de lo posible la frustración de no entender lo que se consulta. Del mismo modo, las características de un entorno virtual deberían dar como resultado entradas que sacaran el máximo partido a la posibilidad de enlazar información, estableciendo vínculos y relaciones entre conceptos y completando la información. 
Por todo lo dicho, según este estudio una ficha lexicográfica especializada online destinada a aprendices debería incluir idealmente -y basándonos para ello en los principios de la e-lexicografía especializada pedagógica, y en las expectativas, necesidades y usos de los usuarios potenciales detectados en este estudio- los campos de 'término', 'término compuesto', 'equivalente', 'categoría gramatical', 'pronunciación' (con transcripción fonética y archivo de audio), 'área temática', 'definición', 'contexto ilustrativo' (a ser posible más de uno y traducido), 'colocaciones' y otras combinaciones frecuentes, 'sinónimos', 'referencias cruzadas' (con hipervínculos a otros términos e incluso, de ser posible, a otras obras), 'abreviatura' (si procede) e 'imagen ilustrativa' (si procede), todo ello de manera clara, lógica y accesible, si bien esto se tratará con más detalle en estudios posteriores.

\subsection{Discusión conjunta/comparada de los resultados más llamativos}

Si contrastamos los datos obtenidos en ambos cuestionarios observaremos que, más frecuentemente de lo que sería deseable, las expectativas y percepciones teóricas de los alumnos parecen no coincidir con sus prácticas reales ni con la realidad lexicográfica que viven.

En lo concerniente a la inclusión en los diccionarios y el uso por parte de los usuarios de información relativa al uso del término en contextos reales, resulta significativo que en el cuestionario 2 (pregunta 14) el 100\% de los alumnos considere muy útil la inclusión de contextos ilustrativos/ejemplos reales de uso cuando, en su día a día, solo un $2 \%$ de alumnos los consulta frecuentemente y un $18 \%$ en ocasiones. Además, según los resultados obtenidos en el ítem 2 del cuestionario 1, sólo en uno de los diccionarios analizados (el 7) un porcentaje significativo (20\%) de alumnos estuvo de acuerdo en que el diccionario en cuestión les ayudaba a saber cómo utilizar el término en contexto. Parece desprenderse de ello que existe un desfase considerable entre la práctica lexicográfica real y el modo 'ideal' en que la concibe el alumno.

Resulta también curioso que, de acuerdo a las preguntas 15 y 16 del cuestionario 2, la mayoría de los estudiantes $(76 \%)$ no considere útil la inclusión de la transcripción fonética del término cuando el 100\% sí reconoce la importancia y utilidad de la inclusión de archivos de audio con el mismo fin. Se considera, pues, importante la información fonética pero se prefieren modos alternativos y más accesibles de presentación de la misma. Con todo, un $74 \%$ de los estudiantes rara vez consulta aspectos relacionados con la pronunciación (pregunta 8-i del cuestionario 2) y, según el cuestionario 1 (ítem 3), solo un $8 \%$ de los estudiantes considera que alguno de los diccionarios analizados -en concreto el 6- tiene cierta utilidad a la hora de mostrarles la pronunciación de un término. Una vez más, las expectativas teóricas no coinciden con las prácticas reales de los aprendices ni con la realidad de los diccionarios de que disponen. 
La importancia otorgada por los alumnos a la consulta de equivalentes en otras lenguas es indudable. Tal y como se desprende del cuestionario 2 (pregunta 8-a), el 98\% de los alumnos consulta frecuentemente los diccionarios en busca de este tipo de información y el 100\% de los mismos considera esta información relevante y útil (pregunta 13, cuestionario 2). Sin embargo, según el ítem 5 del cuestionario 1, solo en el diccionario 5 se consideró por unanimidad que proporcionaban dichos equivalentes, tratándose en el resto de casos de obras monolingües.

Según el ítem 18 del cuestionario 2, el $92 \%$ de los estudiantes considera útil la inclusión de referencias cruzadas pese a que el $96 \%$ rara vez la consulta (ítem 8-d, cuestionario 2). A excepción de en los diccionarios 5 y 6 , ningún alumno pareció tampoco encontrar información acerca del área/subáreas temáticas (ítem 6, cuestionario 1) a las que pertenecía el término. Sin embargo, el ítem 19 del cuestionario 2 muestra que el $68 \%$ de los estudiantes consideran útil esta información pese a consultarla rara vez $76 \%$ (ítem $8-\mathrm{j}$, cuestionario 2). Por otra parte, el $98 \%$ consideró la inclusión de información gramatical poco útil (ítem 21, cuestionario 2), y todos los estudiantes manifestaron consultar ese tipo de información '"rara vez' (ítem 8-g, cuestionario 2).

Es, pues, común que los estudiantes consideren relevantes, importantes o útiles aspectos que no se contemplan debidamente en las obras lexicográficas online de las que disponen, al igual que es frecuente que las percepciones o expectativas de los estudiantes tampoco coincidan con sus prácticas lexicográficas reales, siendo este un aspecto clave a mejorar y fomentar.

\section{CONCLUSIÓN}

Este estudio ha mostrado cómo la lexicografía especializada da lugar a la elaboración de diccionarios especializados, orientados al usuario, con un enfoque comunicativo y social, real (basado en corpus) y de fácil manejo y comprensión (userfriendly), todo ello pudiendo y debiendo aplicarse a las obras de lexicografía pedagógica especializada que, a su vez, presentan sus propias particularidades, máxime cuando se trata de obras online o de e-lexicografía.

Según se ha observado en este estudio, en muchos de los diccionarios online de especialidad analizados encontramos que, ya sea por el tratamiento u ordenación que se hace de la información, por la cantidad o por la calidad de la misma, éstos dejan muchas áreas sin cubrir, las cubren de manera desigual, o bien contienen tan pocos términos que no resultan apenas útiles, resultando casi una casualidad encontrar lo que se busca. Además, no existen obras dentro del ámbito dirigidas específicamente a aprendices, y las múltiples posibilidades del medio digital parecen desaprovechadas en muchos casos, encontrando obras incompletas, con enlaces inactivos o deshabilitados e incluso meras copias replicadas de diccionarios en formato papel. Los propios estudiantes reconocen la funcionalidad del medio digital como un punto a favor de los 
diccionarios online en detrimento del formato papel. Sin embargo, coinciden en que dicha funcionalidad está un tanto desaprovechada en la mayoría de obras analizadas puesto que, por ejemplo, pese a considerar la inclusión de dibujos/fotografías ilustrativos altamente útil, ninguna de las obras analizadas incorpora dicho aspecto entre sus informaciones.

Es también común observar cómo la gran mayoría de los alumnos son conscientes de estar desaprovechando gran parte del potencial ofrecido por los diccionarios debido, sobre todo, a su desconocimiento como usuarios. En aquellas entradas terminológicas densas y con mucha información, los alumnos parecen tener la sensación de encontrarse ante información 'codificada' o 'cifrada' que les resulta de difícil comprensión y por tanto inútil. También sucede a menudo, como ellos mismos apuntan, que informaciones que consideran de utilidad como los ejemplos de uso reales, no aparecen en la entrada. Por ello, el estudiante-usuario prototípico de un diccionario de especialidad parece no sentirse completamente cómodo a la hora de usar un diccionario y reconoce sacar partido solo parcialmente a las obras lexicográficas (especializadas o no) que consulta. Sabe reconocer las deficiencias o debilidades de estas obras y hasta qué punto pueden serle útiles y parece buscar, ante todo, una obra práctica, que refleje las necesidades reales de un usuario no lingüista (y que tampoco pretende serlo) pero que sí querría poder ayudarse de las herramientas a su alcance para su aprendizaje y posterior práctica profesional. Se trata de estudiantes que siguen (y probablemente seguirán viendo) el equivalente traductológico y la definición como las informaciones más valiosas de una entrada terminológica pero que también alcanzan a comprender, especialmente, la importancia del término en uso y su naturaleza colocacional, entre otros aspectos. No obstante, pese a reconocer la importancia de este tipo de informaciones no suelen consultarlas debido principalmente a su desconocimiento.

La gran mayoría de los estudiantes parece estar de acuerdo en que no hay ninguna obra actualmente disponible que aúne todas sus necesidades y reúna todo lo que ellos consideran debe contener una obra lexicográfica especializada de corte pedagógico y online. Por ello, el presente estudio de e-lexicografía ha sido llevado a cabo para ayudarnos a diseñar y elaborar, en estadios posteriores, una propuesta de diccionario online concreta, accesible, acorde a usos y expectativas del usuario potencial, con múltiples posibilidades de recuperación de información, y calidad y cantidad de información, que fomente y contribuya a un aprendizaje significativo y de calidad.

Por último, cabe destacar de nuevo cómo la importancia teórica asignada por los estudiantes a las distintas informaciones contrasta con el uso real dado a los diccionarios. De los resultados se deduce que apenas se consultan muchos de los aspectos considerados importantes, lo que nos indica la necesidad de una reeducación práctica en el uso del diccionario así como la necesidad de formar al lexicógrafo en la e-lexicografía de manera que pueda crear diccionarios online de fácil consulta, 
accesibles, capaces de aprovechar el gran potencial del medio y con toda la información necesaria para nuestros alumnos y futuros profesionales. 


\section{REFERENCIAS BIBLIOGRÁFICAS}

Águila, G. (2009). Los diccionarios electrónicos del español. Madrid: Arco Libros.

Alonso, M. (2013). Colocaciones, diccionario y corpus de aprendices. En M. Casas (Dir.), R. Vela (Ed.), Eugenio Coseriu, in memoriam, XIV Jornadas de Lingüística (pp.57-71). Cádiz: Servicio de Publicaciones de la Universidad.

Alvar, M. (2009). Los periodistas son responsables del buen uso de la lengua por la influencia que ejercen. Entrevista aparecida en el diario El Día el 3 de mayo de 2009.

Azorín, D. \& Climcnt, J. (2003). El diccionario como instrumento didáctico en la enseñanzal aprendizaje de E/LE. Resultados de una encuesta. En Actas de Asociación española de Lingüistica Aplicada (AESLA). Universidad de Lugo.

Baxter, J. (1980). The dictionary and language Behaviour: A single word or a handful? TESOL Quarterly, 14(3), 325-336

Bergenholtz, H. \& Tarp, S. (2003). Two opposing theories: On H. E. Wiegand's Recent Discovery of Lexicographic Functions. Hermes. Journal of Linguistics, 31, 171-196.

Bergenholtz, H. \& Tarp, S. (2004). The concept of dictionary usage. Nordic Journal of English Studies, Special Issue, 3(1).

Binon, J. \& Verlinde, S. (1999). La contribution de la lexicographie pédagogique à l'apprentissage et à l'enseignement d'une langue étrangère ou seconde. Etudes de linguistique appliqué, 116, 453-468.

Bogaards, P. (1994). Le vocabulaire dans l'apprentissage des langues étrangères. Paris: Éditions Didier.

Cabré, M. T. (1993). La Terminología: Teoría, metodología, aplicaciones. Barcelona: Editorial Antártida/Empúries.

Cabré, M. T. (2009). Terminología y buenas prácticas, Atti Convegno Assiterm, Publifarum, n. 12 [en línea]. Disponible en: http://publifarum.farum.it/ezine articles.php?id=161

Ciro, L. A. (2007). El diccionario como objeto de estudio y herramienta didáctica en la enseñanza de la lengua. El Ágora USB Medellín-Colombia, 7(1), 57-64.

Corpas, G., Leiva, J. \& Valera, M. J. (2001). El papel del diccionario en la formación de traductores e intérpretes: Análisis de necesidades y encuestas de uso. En M. C. Ayala (Coord.), Diccionario y enseñanza (pp. 239-273). Alcalá: Servicio de Publicaciones de la Universidad. 
Edo Marzá, N. (2009). The specialised lexicographical approach: A step further in dictionarymaking. Serie Linguistic Insights. Bern: Peter Lang.

Fathi, B. (2014). Experts and specialised lexicography: Perspectives and needs. Terminàlia, 9, 12-21.

Fuertes-Olivera, P. A. (2009). Specialised lexicography for learners: Specific proposals for the construction of pedagogically-oriented printed business dictionaries. Hermes. Journal of Language and Business Communication, 42, 167-188.

Fuertes-Olivera, P. A. \& Arribas-Baño, A. (2008). Pedagogical specialised lexicography. The representation of meaning in business and Spanish business dictionaries. Amsterdam/Philadelphia: John Benjamins.

Fuertes-Olivera, P. A. \& Bergenholtz, H. (Eds.) (2011). E-Lexicography. The Internet, digital initiatives and lexicography. Londres, Reino Unido. Continuum.

Herbst, T. \& Stein, G. (1987). Dictionary-using skills: A plea for a new orientation in language teaching. En A. P. Cowie, (Ed.), The Dictionary and the Language Learner- Papers from the Euralex Seminar at the University of Leeds (pp. 115-127). Tübingen: Niemeyer.

Hernández, H. (2008). Retos de la lexicografía didáctica española. Alicante: Biblioteca Virtual Miguel de Cervantes.

Martín, A. (2001). Competencia curricular y diccionario: Propuesta teórica. Contextos Educativos. Revista de educación, 4, 315-328.

Martínez, M. R. (2004). El diccionario de L2 que «deseamos». En M. A. Castillo (Coord.), Las gramáticas y los diccionarios en la enseñanza del español como segunda lengua, deseo y realidad: Actas del XV Congreso Internacional de ASELE (pp. 573579). Sevilla: Universidad de Sevilla.

Rosa (de la), R. (2003). Los estudiantes de traducción y el uso de los diccionarios. Interlingüistica, 14, 289-304.

Santamaría, I. (2004). La información gramatical en los diccionarios monolingües de aprendizaje: Reflexiones a partir del verbo. Estudios de lingüistica: El verbo, 1, 559-580.

Selva, T., Verlinde, S. \& Binon, J. (2003). Vers une deuxième génération de dictionnaires électroniques. In Les dictionnaires électroniques. Traitement automatique des langues, 44(2), 177-197.

Snell-Hornby, M. (1987). Towards a learner's bilingual dictionary. En A. P. Cowie, (Ed.), The Dictionary and the Language Learner. Papers from the Euralex Seminar at the University of Leeds (pp. 159-170). Tübingen: Niemeyer. 
Tarp, S. (2005). Desafíos para la lexicografía especializada. En P.A. Fuertes-Olivera (Ed.), Lengua y Sociedad: Investigaciones Recientes en Lingüistica Aplicada (pp. 205232). Valladolid: Servicio de Publicaciones e Intercambio Editorial de la Universidad de Valladolid.

Tarp, S. (2008). Lexicography in the Borderland between Knowledge and Non-knowledge. General Lexicographical Theory with particular Focus on Learner's Lexicography. Tübingen: Niemeyer.

Tarp, S. (2013). Necesidad de una teoría independiente de la lexicografía: El complejo camino de la lingüística teórica a la lexicografía práctica. Círculo de Lingüística Aplicada a la Comunicación, 56, 110-154.

\section{NOTAS}

${ }^{1}$ La asignatura EX/AG 1005 se imparte en primer curso de los grados de Ingeniería Eléctrica, Mecánica, Química, Agroalimentaria y del Medio Rural e Ingeniería en Tecnologías Industriales de la Universitat Jaume I de Castellón (España). A los estudiantes se les presupone un nivel mínimo de partida A2 según el Marco Común Europeo de Referencia para las Lenguas (MCER o CEFR, en inglés) y se espera de ellos haber consolidado un B2 al finalizar la asignatura.

2 Muchos tipos de información que consideramos relevante para nuestros usuarios potenciales no se incluyen en los diccionarios/glosarios analizados por no ser propias del tipo de obra en sí (por ejemplo, son habituales los diccionarios monolingües, es decir, sin equivalentes). 